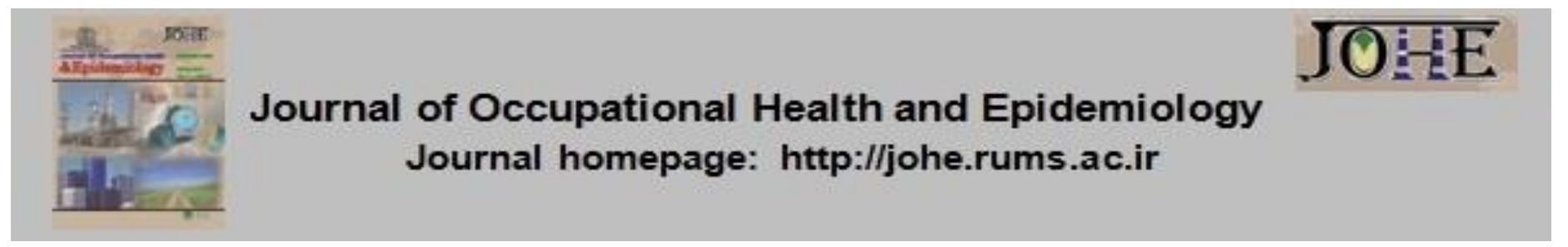

\title{
Assessment of Noise Effect on Employee Comfort in an Open-Plan Office: Validation of an Assessment Questionnaire
}

\author{
Mohammad Javad Sheikhmozafari ${ }^{1}$, Parsa Mohammad Alizadeh ${ }^{1}$, Omran Ahmadi²*, Behnaz \\ Mazloomi ${ }^{3}$
}

1. MSc in Occupational Health and Safety Engineering, Faculty of Medical Sciences, Tarbiat Modares University, Tehran, Iran.

2. Assistant Prof., Dept. of Occupational Health and Safety Engineering, Faculty of Medical Sciences, Tarbiat Modares University, Tehran, Iran.

3. BSc in Occupational Health and Safety Engineering, School of Public Health, Bam University of Medical Sciences, Bam, Iran.

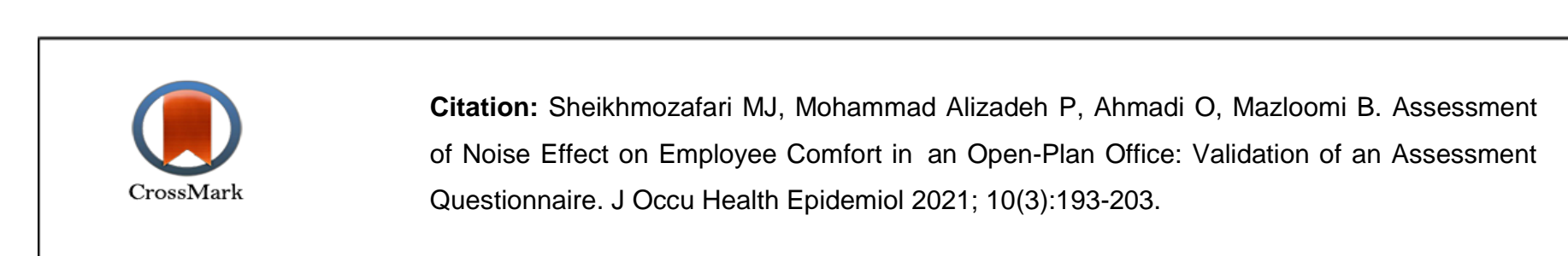

\section{Article Info}

* Corresponding author:

Omran Ahmadi,

E-mail:

o.ahmad@modares.ac.ir

\section{Article history}

Received: Aug 2021

Accepted: Nov 2021

10.52547/johe.10.3.193

Print ISSN: 2251-8096 Online ISSN: 2252-0902

Peer review under responsibility of Journal of Occupational Health and Epidemiology

\begin{abstract}
Background: Today, open-plan offices are among the most common work environments. Although the noise in these environments is usually below the standard level, it is one of the critical annoyance factors due to the nature of the mental work. Accordingly, this study aimed to assess noise effects on employee comfort and validate the Persian version of the assessment of noise effects on employee comfort in the open-plan office questionnaire in Iran.

Materials \& Methods: The present descriptive study was conducted in an open-plan office in Shiraz, in 2021. We distributed questionnaires among 66 employees. Besides, we translated the questionnaire using the backward-forward technique, with the alpha coefficient and the intra-class correlation used to measure reliability. Finally, we used the Kappa, Spearman, and Mann-Whitney tests in SPSS V22.0 for data analysis.

Results: The validity of the questionnaire items was evaluated as acceptable using Kappa and Spearman's coefficients. Besides, the reliability of the questionnaire, using the ICC and the alpha coefficient, was 0.876 and 0.930 , respectively. In this study, the employees were sensitive to noise, and their overall satisfaction with their physical conditions was moderate. In total, $47 \%$ of the employees considered the noise level of their working environment high and very high, and 35\% considered it annoying or very annoying.

Conclusions: The findings of the present study showed that the questionnaire was an effective and reliable tool for noise annoyance assessments in office environments. Besides, we can use this tool to determine improvements required in open-plan offices and to evaluate the efficiency of these improvements.
\end{abstract}

Keywords: Hearing, Noise, Questionnaire, Validation.

\section{Introduction}

Noise is an unwanted sound affecting people's physical and mental health [1]. Today, noise pollution is one of the major problems in societies, which affects the quality of all people's life [2]. The effects of noise on human health and the environment are increasing so dramatically that if left uncontrolled, it can lead to hazardous conditions [3]. To enumerate some noise effects on human health, one can refer to hearing loss, social irritability, speech disorders, sleep disorders, cardiovascular disorders, mental disorders, metabolic disorders, cancer exacerbation, oxidative stress, concentration reduction at work, 
and the like [4-6]. Noise has always been the main detrimental factor in work environments. Besides, in work environments where speech communication is one of the main ways to communicate, noise can be very annoying [2]. Nowadays, to make better use of available space and to consider economic aspects, open-plan offices are among the most common working environments [7]. Since the formation of open-plan offices, their acoustic problems have been among the major causes of job dissatisfaction. Although office employees experience noise below the hazardous level, their productivity can decrease by $66 \%$ when they are exposed to conversations of their colleagues [8]. The noise level in open-plan offices usually varies between 46 and $58 \mathrm{~dB}$. In general, if the background noise level exceeds 45 $\mathrm{dB}$, people's acoustic satisfaction will decrease [9]. Other problems of open-plan offices, except acoustic problems, include their effects on people's well-being, job satisfaction, and job performance [10]. A study reported that noise has a negative effect on office employees' productivity [11]. Haapakangas stated that noise had a negative effect on employees' ability to focus on the manner of performing their tasks [12]. In addition, Seddigh reported that office noise increased frustration and stress among employees [13]. A study reported noise as the sixth most important factor and the second annoying physical factor in the workplace in terms of comprehensibility, with $31 \%$ of employees having been dissatisfied with their workplace noise [9]. Oseland stated that $92 \%$ of employees reported that noise made their job performance less productive [14]. Other studies show that the conversation between individuals and their colleagues is the primary source of noise annoyance for other employees [10, 15, 16]. lannace examined the effects of noise, heat, and ventilation systems in open-plan offices on employee comfort, According to him, when ventilation systems are active and inactive, the noise level reaches about 49 and $39 \mathrm{~dB}$, respectively, which shows a significant difference [8]. Haapakanga found that the noise produced by conversations among employees plays a significant role in other employees' overall perception of noise [10]. Nezami found that the primary source of noise annoyance was the noise of conversations among people with each other, which led to a decrease in people's concentration and perception [7]. ČEKAN evaluated noise effects on employee comfort in an open-plan office [2]. Blasio reported that unnecessary and irrelevant conversations among people led to a rise in acoustical annoyance and the prevalence of symptoms related to mental health, which decreased job performance and wellbeing among employees in open-plan offices [15]. Similarly, Pierrette reported that background noise levels were high in the workplace, with unnecessary and irrelevant conversations among colleagues being the primary source of noise annoyance in openplan offices [17]. In the same vein, many other studies have been conducted on the effects of noise on office employees [18-22].

ISO 3382-3 2012 (En) fully describes the method of measuring acoustic parameters in open-plan offices [23]. This standard considers the factors affecting the acoustic performance of open-plan offices, including the layout, acoustic absorption coefficient, and background noise. However, the way people in that environment perceive the noise of their work environment has not been taken into account. It has been stated in some studies that the perceived noise level by employees contributes to their overall perceived noise annoyance only by 20 to $25 \%$, so other important factors must be considered as well. Thus, we should consider the factors, such as the source (s) of noise, the type of tasks performed by employees, noise sensitivity among individuals, and the work environment in studying and evaluating the noise annoyance occurring in open-plan offices [17]. All of the abovementioned factors emphasize the importance of the subjective assessment of noise by individuals and the need for a reliable tool for collecting required data. Since objective noise assessments using measurement devices do not consider the noise annoyance caused by people, mental evaluation must be carried out. Besides, the use of such tools is easier, faster, and cheaper, being possibly doable by people working in that work environment [24]. Questionnaires are among the most reliable tools for mental and qualitative noise assessments in the workplace. Pierrette developed a questionnaire and proved its validity and reliability. Many studies have used this type of questionnaire [10,12, 15, 18, 24-28]. Using this questionnaire, Braat found that $38 \%$ of people suffered from noise annoyance in their work environment. Besides, he showed a significant relationship between acoustic characteristics of the environment and noise annoyance [29]. N. Perrin et al, using this questionnaire, found that $56 \%$ of employees considered their office noise high, and $58 \%$ considered it annoying [30]. Since there is no reliable tool to be used for physical evaluation in open-plan offices in Iran, we decided to localize and validate this questionnaire in our country. To use and localize a questionnaire from the original language into Persian, we should first examine its validity and reliability. Against this backdrop, the present study aims to assess noise effects on 
employee comfort; to this end, we translated and validated the Persian version of the questionnaire on the assessment of noise effects on employee comfort in open-plan offices in Shiraz, Iran.

\section{Materials and Methods}

The present descriptive-analytical study was conducted in 2021. Out of the total 79 employees working in the open-plan office in Shiraz, we selected 66 employees using an online sample size calculator for assessment. To use a questionnaire in the original language, two steps must be taken. Firstly, its linguistic validity must be determined, which was done by translating the questionnaire from the original language into Persian. Secondly, the psychometric aspects of the questionnaire must be examined. Linguistic validation and psychometric validation include the translation and cross-cultural adaptation processes of a tool into the target language so that the tool remains conceptually and semantically equivalent to the source version. Both aforementioned steps are complementary and taken to ensure the equivalents of the translated and original versions. In the first step, we are supposed to translate the original questionnaire to determine its linguistic validity. There are two methods to translate each questionnaire from the original language into another language, which include forward-backward (FB) and dual-panel (DP) methods. Accordingly, we used the backward-forward method to prepare and translate the questionnaire from the original language into Persian [31]. In this technique, two separate experts translated the items in this questionnaire into Persian. In the next step, two Persian language experts fluent in the English language translated the Persian questionnaires into the original language, i.e. English, without seeing the first original version. Next, after checking the linguistic and content validity of the second questionnaire translated into English, we merged the translations with the original version of the questionnaire and produced the final version of the questionnaire.

In addition, we used SPSS V22.0 to analyze the data. To evaluate the reliability of the questionnaire, we used the intra-class correlation coefficient (ICC) test and the alpha coefficient. Besides, to use the ICC test, a single group answered the questionnaire items twice under the same conditions. In addition, using the ICC test, the scores obtained were compared and used as a reliability coefficient. We also used the Kappa and Spearman's correlation coefficients to evaluate the validity of the questionnaire items. Other statistical analyses were done using Mann-Whitney and Spearman's tests.

In this study, we used the random sampling method. To determine the sample size, Cochran's formula was used. We distributed the final questionnaires among 66 employees of an openplan office in Shiraz. At first, we briefed the occupational health officer on all conditions and objectives of the study in that office. Next, after talking to the staff and explaining the objectives of the study, the individuals participated in the study voluntarily. The inclusion criteria were having at least one year of work experience, having no mental illness, having normal hearing, and not being pregnant. On the other side, the exclusion criteria included taking certain medical drugs, suffering from congenital hearing impairment, and completing the questionnaire improperly.

The questionnaire on the assessment of noise effects on employee comfort in open-plan offices: The questionnaire generally consisted of 4 sections and 67 questions. The 5 sections of the questionnaire included studying the demographic information of the people and their workplace, assessing physical conditions of the work environment, assessing the ambient noise in the workplace, examining the relationship between employees and noise (at home, at work, and when sleep), and examining the health effects of noise on employees.

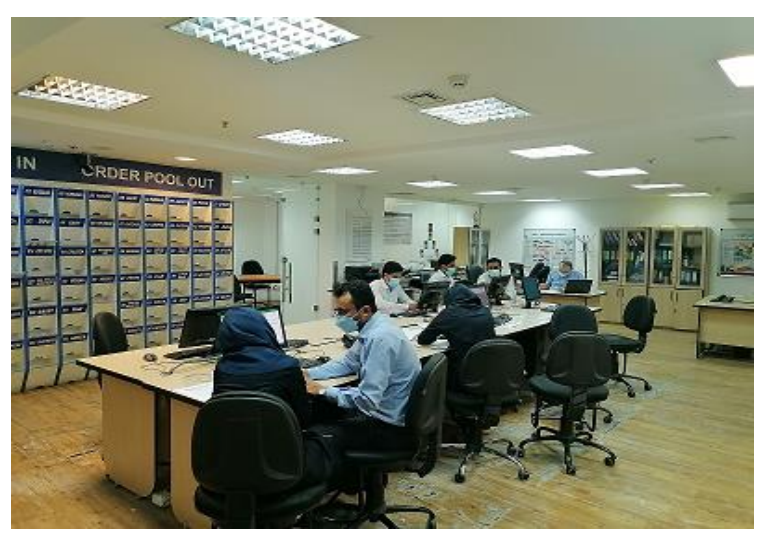

Fig. 1. A view of the studied open-plan office and its employees 
In the first part of the questionnaire, general information about people and their workstation, such as gender, age, work experience in the office, work experience in the current position, number of people working in the workstation (room), and job duties were considered. In the first part of the questionnaire, people's job satisfaction with physical conditions of their work environment was evaluated as well.

There were a total of 14 items for measuring job satisfaction on a 5-point scale (from $1=$ not satisfactory at all to $5=$ quite satisfactory). These 14 items measured satisfaction based on the two dimensions of control/privacy (7 items) as well as comfort/functionality ( 7 items). For the dimension of control/privacy, "possibilities available for noise control" were considered, and for the comfort/functionality dimension, "equipment available in the workspace" was mentioned. After studying the answers to job satisfaction questions among the employees in terms of physical conditions of the work environment on a 5-point scale, three responses were obtained, being "average global satisfaction", "average control/privacy satisfaction", and "average comfort/functionality satisfaction".

The second part of the questionnaire evaluated environmental noise made by the employees in the workplace. In the first step, the overall perceived noise level by the individuals and then the overall noise annoyance level were assessed. In this part of the questionnaire, environmental noise was broken down into 5 noise sources that included operating machines (ventilation, computers, printers, etc.), ringing telephones, intelligible conversations, unintelligible conversations, and walking people. This classification was based on the frequency of noise perception, the level of annoyance generated by each single noise, effects of these noises on the work, and if these noises were more annoying for some tasks than others. Several studies have mentioned these five noise sources as the primary sources of noise annoyance in open-plan offices [17, 32]. The perception frequency was assessed on a 5-point scale $(1=$ never to $5=$ permanently). Besides, annoyance was assessed on a 5 -point scale ( $1=$ not annoying at all to $5=$ quite annoying). Next, the employees were asked to give "yes" or "no" answers to the question if the given noise was more annoying for some work activities, and if yes, the employees were supposed to mention the activities.

In the next step, the employees were asked to sort the noise sources from the most annoying to the least annoying ones. In addition to the five noise sources mentioned above, two other sources were added, including the noise produced by people (keyboards a well as opening and closing drawers) and the noise related to a specific person.

In the third part of the questionnaire, the participants' reactions to the noise or their sensitivity to the noise were assessed. In this section, four separate questions were asked about each of the three subjects, i.e. sleep, personal habits, and work, which totaled 12 questions. These 12 questions examined the individuals' agreement with the question on a 4-point scale (1 = strongly disagree to $4=$ strongly agree). The score for each question ranged from 0 to 3 , which was considered as the noise sensitivity score. A score less than 1.1 indicated that the person was not sensitive to noise, and a score more than 1.63 indicated that the person was sensitive to noise.

The last (fourth) part of the questionnaire assessed the way the employees perceived their own health. This section, which included 15 questions, allowed the employees to assess their physical and mental health. These questions were used to calculate the general perceived health score of the employees, with the respondents having been supposed to express their agreement with the questions on a 5point scale. This section calculated 4 specific scores for factors, including perceived physical health, perceived psychological health, perceived symptoms, and perceived stress. The scores in this section ranged from 1 to 5 , with a score closer to 1 meaning very poor health, and a score closer to 5 indicating very satisfactory conditions. In other words, scores greater than or equal to 3.5 indicated good health, scores greater than or equal to 2.5 and less than 3.5 indicated moderate health, and scores less than 2.5 indicated poor health. The scores were reversed for the last 10 questions.

The present article is the result of a research project approved by the Ethics Committee of Tarbiat Modares University, Tehran, Iran (IR.MODARES.REC.1400.195).

\section{Results}

In this study, 66 employees (44 men and 22 women) working in an open-plan office in Shiraz were surveyed. The participants' average age was 33 years $( \pm 6.75)$, which indicated that the study population was young. The average work experience of the participants was about 6 years. A total of $52 \%$ of the people confirmed they had a fixed workstation. Besides, $35 \%, 32 \%$, and $11 \%$ of the employees confirmed that 7 to 15,3 to 6 , and 16 to 49 people in their workstations worked together, respectively. The reliability of the questionnaire was determined using the ICC and 
alpha coefficients of 0.876 and 0.930 . The closer the ICC was to 1, the greater the reliability would be. Table 1 lists the reliability values of all questions. Table 2 shows validation results for the answers given by the employees for the first and second series of questions using the Kappa and Spearman's tests. It should be noted that we used the Kappa and Spearman's tests to examine the agreement and the correlation between employees' responses, respectively.

Table 1. Questionnaire reliability results using ICC and alpha coefficients

\begin{tabular}{|c|c|c|}
\hline Questions & ICC & Alpha \\
\hline Environment noise & 0.922 & 0.959 \\
\hline Concentration possibilities & 0.848 & 0.918 \\
\hline Lighting quality & 0.967 & 0.983 \\
\hline Workstation physical position & 0.818 & 0.900 \\
\hline Private conversation possibilities & 0.874 & 0.933 \\
\hline Managing noise possibilities & 0.933 & 0.965 \\
\hline Furniture in the work area & 0.893 & 0.943 \\
\hline Possibility of watching outside & 0.912 & 0.954 \\
\hline Cleanliness of the work area & 0.905 & 0.950 \\
\hline Equipment available in the work area & 0.919 & 0.958 \\
\hline Possibilities of controlling the temperature & 0.865 & 0.928 \\
\hline Air circulation in the work area & 0.833 & 0.909 \\
\hline Personalizing work area possibilities (with personal objects, photos, etc.) & 0.691 & 0.817 \\
\hline Possibility of not being seen by other people & 0.809 & 0.894 \\
\hline Overall noise level in the work environment & 0.937 & 0.968 \\
\hline Overall noise level annoying the workplace & 0.840 & 0.913 \\
\hline Noise of operating machines & 0.856 & 0.922 \\
\hline Annoying noise levels of operating machines & 0.855 & 0.922 \\
\hline Noise levels of telephones ringing & 0.899 & 0.947 \\
\hline Annoying noise levels of telephones ringing & 0.928 & 0.963 \\
\hline Noise levels of intelligible conversations & 0.794 & 0.885 \\
\hline Annoying noise levels of intelligible conversations & 0.973 & 0.986 \\
\hline Noise levels of unintelligible conversations & 0.809 & 0.894 \\
\hline Annoying noise levels of unintelligible conversations & 0.872 & 0.932 \\
\hline Noise levels of walking people & 0.836 & 0.911 \\
\hline Annoying noise levels of walking people & 0.849 & 0.918 \\
\hline Quiet environment for night sleep & 0.874 & 0.933 \\
\hline Quiet environment for carrying out new tasks & 0.879 & 0.936 \\
\hline Getting used to noise at home & 0.889 & 0.941 \\
\hline Getting very agitated when hearing someone speak, when trying to sleep & 0.905 & 0.950 \\
\hline Sensitivity to the neighbor's noise & 0.935 & 0.966 \\
\hline Feeling it difficult to do the work in case of noisy people & 0.896 & 0.945 \\
\hline Putting in a bad performance in noisy environments & 0.807 & 0.893 \\
\hline Not feeling alert when bothered by noise the night before & 0.923 & 0.960 \\
\hline Living on a noisy street & 0.809 & 0.894 \\
\hline Accepting disadvantages to live in a quiet place & 0.910 & 0.953 \\
\hline Needing peace and quiet to carry out a difficult task & 0.820 & 0.901 \\
\hline Sleeping even if it is noisy & 0.836 & 0.911 \\
\hline Overall perceived health & 0.951 & 0.975 \\
\hline Overall perceived health compared to the last year & 0.963 & 0.981 \\
\hline Overall perceived morale & 0.905 & 0.951 \\
\hline Overall confidence in the future & 0.875 & 0.933 \\
\hline Feeling fully energetic & 0.768 & 0.869 \\
\hline Having back pain or neck pain & 0.977 & 0.988 \\
\hline Having pain in the arm (from shoulders to hands) & 0.931 & 0.964 \\
\hline Having pain in the leg area & 0.939 & 0.969 \\
\hline Having difficulty sleeping & 0.870 & 0.930 \\
\hline Having a headache & 0.925 & 0.961 \\
\hline Digestive problems (heartburn, bloating, diarrhea) & 0.873 & 0.932 \\
\hline Chest pains & 1 & 1 \\
\hline Having job stress & 0.773 & 0.872 \\
\hline Feeling exhausted & 0.746 & 0.854 \\
\hline Having job exhaustion & 0.811 & 0.895 \\
\hline
\end{tabular}


Table 2. Validation of the answers given by the employees for the first and second series of questions

\begin{tabular}{|c|c|c|c|}
\hline Questions & $\begin{array}{l}\text { Agreement } \\
\text { (Kappa test) }\end{array}$ & $\begin{array}{l}\text { Correlation } \\
\text { (Spearman's } \\
\text { coefficient) }\end{array}$ & P-value \\
\hline Environment noise & 0.724 & 0.891 & $0.05>$ \\
\hline Concentration possibilities & 0.605 & 0.863 & $0.05>$ \\
\hline Lighting quality & 0.907 & 0.990 & $0.05>$ \\
\hline Workstation physical position & 0.662 & 0.805 & $0.05>$ \\
\hline Private conversation possibilities & 0.783 & 0.870 & $0.05>$ \\
\hline Managing noise possibilities & 0.810 & 0.952 & $0.05>$ \\
\hline Furniture in the work area & 0.672 & 0.806 & $0.05>$ \\
\hline Possibility of watching outside & 0.659 & 0.953 & $0.05>$ \\
\hline Cleanliness of the work area & 0.627 & 0.922 & $0.05>$ \\
\hline Equipment available in the work area & 0.706 & 0.922 & $0.05>$ \\
\hline Possibilities of controlling the temperature & 0.904 & 0.801 & $0.05>$ \\
\hline Air circulation in the work area & 0.688 & 0.825 & $0.05>$ \\
\hline $\begin{array}{l}\text { Personalizing work area possibilities (with personal objects, } \\
\text { photos etc.) }\end{array}$ & 0.694 & 0.714 & $0.05>$ \\
\hline Possibility of not being seen by other people & 0.659 & 0.857 & $0.05>$ \\
\hline Overall noise levels in the work environment & 0.724 & 0.943 & $0.05>$ \\
\hline Overall noise levels annoying the workplace & 0.613 & 0.857 & $0.05>$ \\
\hline Noise of operating machines & 0.696 & 0.862 & $0.05>$ \\
\hline Annoying noise levels of operating machines & 0.702 & 0.829 & $0.05>$ \\
\hline Noise levels of telephones ringing & 0.729 & 0.905 & $0.05>$ \\
\hline Annoying noise levels of telephones ringing & 0.731 & 0.933 & $0.05>$ \\
\hline Noise levels of intelligible conversations & 0.679 & 0.848 & $0.05>$ \\
\hline Annoying noise levels of intelligible conversations & 0.831 & 0.977 & $0.05>$ \\
\hline Noise levels of unintelligible conversations & 0.681 & 0.799 & $0.05>$ \\
\hline Annoying noise levels of unintelligible conversations & 0.706 & 0.854 & $0.05>$ \\
\hline Noise levels of walking people & 0.667 & 0.776 & $0.05>$ \\
\hline Annoying noise levels of walking people & 0.690 & 0.867 & $0.05>$ \\
\hline Quiet environment for night sleep & 0.783 & 0.893 & $0.05>$ \\
\hline Quiet environment for carrying out new tasks & 0.715 & 0.876 & $0.05>$ \\
\hline Getting used to noise at home & 0.800 & 0.894 & $0.05>$ \\
\hline $\begin{array}{l}\text { Getting very agitated when hearing somebody speak, when trying } \\
\text { to sleep }\end{array}$ & 0.685 & 0.905 & $0.05>$ \\
\hline Sensitivity to the neighbor's noise & 0.815 & 0.949 & $0.05>$ \\
\hline Finding it difficult to do the work in case of noisy people & 0.717 & 0.865 & $0.05>$ \\
\hline Putting in a bad performance in noisy environments & 0.603 & 0.828 & $0.05>$ \\
\hline Not feeling alert when bothered by noise the night before & 0.806 & 0.949 & $0.05>$ \\
\hline Living on a noisy street & 0.643 & 0.773 & $0.05>$ \\
\hline Accepting disadvantages to live in a quiet place & 0.797 & 0.874 & $0.05>$ \\
\hline Needing peace and quiet to carry out a difficult task & 0.679 & 0.806 & $0.05>$ \\
\hline sleeping even if it is noisy & 0.676 & 0.783 & $0.05>$ \\
\hline Overall perceived health & 0.899 & 0.994 & $0.05>$ \\
\hline Overall perceived health compared to the last year & 0.903 & 0.945 & $0.05>$ \\
\hline Overall perceived morale & 0.746 & 0.852 & $0.05>$ \\
\hline Overall confidence in the future & 0.754 & 0.932 & $0.05>$ \\
\hline Feeling fully energetic & 0.609 & 0.812 & $0.05>$ \\
\hline Having back pain or neck pain & 0.898 & 0.943 & $0.05>$ \\
\hline Having pain in the arm (from shoulders to hands) & 0.877 & 0.982 & $0.05>$ \\
\hline Having pain in the leg area & 0.884 & 0.912 & $0.05>$ \\
\hline Having difficulty sleeping & 0.762 & 0.890 & $0.05>$ \\
\hline Having a headache & 0.727 & 0.877 & $0.05>$ \\
\hline Digestive problems (heartburn, bloating, and diarrhea) & 0.800 & 0.994 & $0.05>$ \\
\hline Chest pains & 1 & 1 & $0.05>$ \\
\hline Having job stress & 0.662 & 0.797 & $0.05>$ \\
\hline Feeling exhausted & 0.691 & 0.774 & $0.05>$ \\
\hline Having job exhaustion & 0.662 & 0.809 & $0.05>$ \\
\hline
\end{tabular}

The average score obtained from the noise sensitivity assessment section was $1.80( \pm 0.4)$. Besides, the reliability values of this part of the questionnaire using the ICC and the alpha coefficient were 0.87 and 0.93 , respectively.

In addition, the overall score obtained from the perceived health assessment section was 4.18 ( \pm
0.45). The reliability values of this part of the questionnaire using the ICC and the alpha coefficient were 0.89 and 0.94 , respectively.

The score of the overall satisfaction with the workplace was 2.895 ( \pm 0.76). Besides, we examined the scores of this section according to the two dimensions of control/privacy and 
comfort/functionality separately, which were 2.787 $( \pm 0.87)$ and $3( \pm 0.78)$, respectively. Reliability values of the overall satisfaction assessment with the workplace using the ICC and the alpha coefficient were 0.87 and 0.93 , respectively. Besides, reliability values for the control/privacy and comfort/functionality dimensions were 0.84 and 0.91 as well as 0.90 and 0.95 , respectively. Concerning the employees' perception of workplace noise, $47 \%$ (almost half of them) considered the noise level of their work environment high $(27 \%)$ or very high $(20 \%)$, and $35 \%$ of the people considered that annoying (23\%) or very annoying (12\%) (Figs. 2 and 3 ).

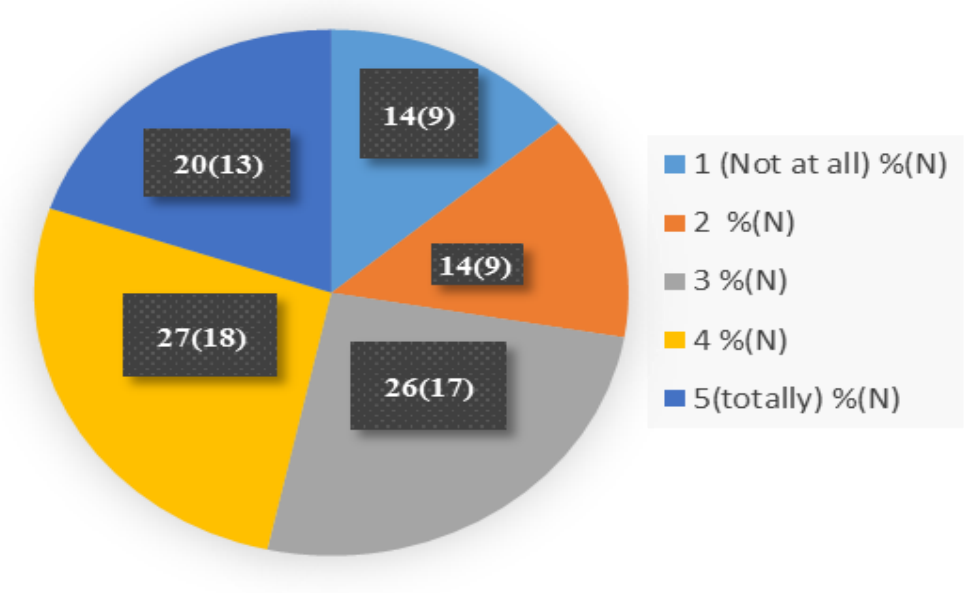

Fig. 2. Employees' perception of the noise level in the workplace $(N=66)$

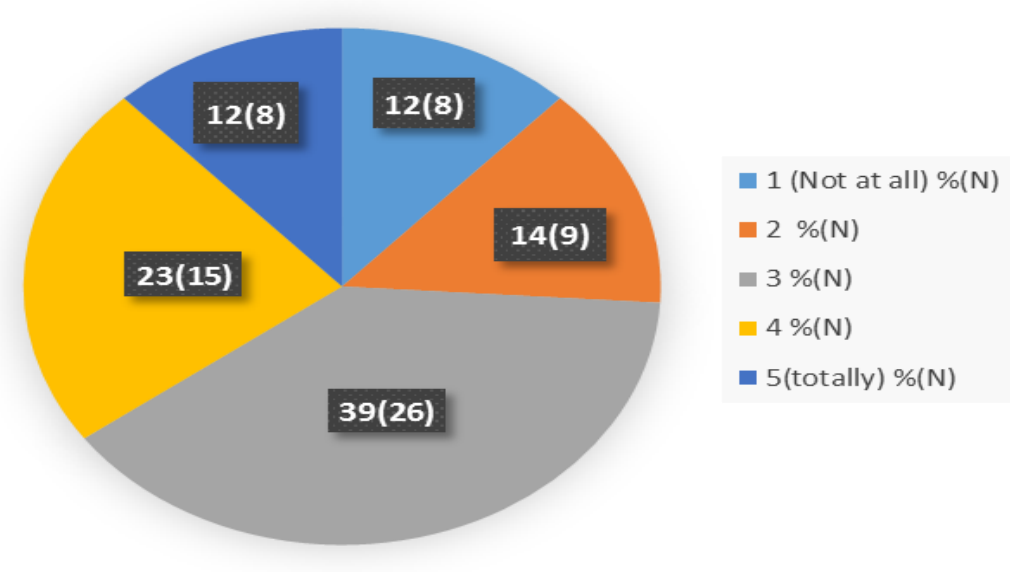

Fig. 3. Employees' perception of noise annoyance in the workplace $(N=66)$

The results of the Spearman's statistical test indicated that the noise level perceived and the annoyance felt were positively and strongly related $\left(C_{c}=0 \times 7, P<0 \times 001\right)$.

We requested the employees to assess the frequency of various noise sources present in their workplace. Accordingly, it seemed that all five noise sources in the workplace more or less existed in the environment and had a high significance (Table 3). Besides, the noise source heard most frequently was the telephone ringing sound with $32 \%$, which was constantly heard by the employees.

Table 3. Frequency of the perception of different noise sources

\begin{tabular}{lccccc}
\hline $\begin{array}{l}\text { Noise sources } \\
(\mathbf{N}=\mathbf{6 6})\end{array}$ & $\begin{array}{c}\mathbf{1}(\mathbf{N e v e r}) \\
\mathbf{\%}(\mathbf{N})\end{array}$ & $\begin{array}{c}\mathbf{2} \\
\mathbf{\%}(\mathbf{N})\end{array}$ & $\begin{array}{c}\mathbf{3} \\
\mathbf{\%}(\mathbf{N})\end{array}$ & $\begin{array}{c}\mathbf{4} \\
\mathbf{\%}(\mathbf{N})\end{array}$ & $\begin{array}{c}\mathbf{5} \\
\text { (Permanently) } \\
\mathbf{\%}(\mathbf{N})\end{array}$ \\
\hline Office machinery & $21(14)$ & $17(11)$ & $33(22)$ & $17(11)$ & $12(8)$ \\
\hline Telephones ringing & $21(14)$ & $9(6)$ & $21(14)$ & $17(11)$ & $32(21)$ \\
\hline Intelligible conversations & $17(11)$ & $6(4)$ & $27(18)$ & $26(17)$ & $24(16)$ \\
\hline Non-intelligible conversations & $17(11)$ & $18(12)$ & $36(24)$ & $21(14)$ & $8(5)$ \\
\hline Walking people & $23(15)$ & $11(7)$ & $24(16)$ & $21(14)$ & $21(14)$ \\
\hline
\end{tabular}


Table 4. Noise annoyance from different noise sources

\begin{tabular}{lccccc}
\hline $\begin{array}{l}\text { Noise sources } \\
\text { (N=66) }\end{array}$ & $\begin{array}{c}\mathbf{1} \text { (Not at all) } \\
\mathbf{\%}(\mathbf{N})\end{array}$ & $\begin{array}{c}\mathbf{2} \\
\mathbf{\%}(\mathbf{N})\end{array}$ & $\begin{array}{c}\mathbf{3}(\mathbf{N}) \\
\mathbf{4}(\mathbf{N})\end{array}$ & $\begin{array}{c}\mathbf{5}(\text { Totally) } \\
\mathbf{\%}(\mathbf{N})\end{array}$ \\
\hline Office machinery & $22(13)$ & $22(13)$ & $35(21)$ & $13(8)$ & $8(5)$ \\
\hline Telephones ringing & $32(21)$ & $23(15)$ & $18(12)$ & $14(9)$ & $12(8)$ \\
\hline Intelligible conversations & $30(19)$ & $13(8)$ & $33(21)$ & $11(7)$ & $14(9)$ \\
\hline Non-intelligible conversations & $23(14)$ & $21(13)$ & $31(19)$ & $18(11)$ & $7(4)$ \\
\hline Walking people & $36(21)$ & $24(14)$ & $31(18)$ & $8(5)$ & $2(1)$ \\
\hline
\end{tabular}

When the employees assessed annoyance levels, intelligible conversations and telephones ringing were the most annoying noise sources (Table 4). For each of the five noise sources, we performed the Spearman's statistical test to find the relationship between the perception frequency and perception annoyance caused by that source. Accordingly, it turned out that there was a significant direct relationship between frequency and annoyance factors for each of the sources.

When the employees declared that they were annoyed by a specific noise source, we asked them to indicate (with a yes or no answer) whether they considered the annoyance to be more important depending on the task they were performing (such as reading, writing, reading, etc.). If their answer was yes, they were supposed to list the tasks. We found that $32 \%$ of the employees were distracted by operating machines, $34 \%$ by telephones ringing, $26 \%$ by intelligible conversations, $25 \%$ by non-intelligible conversations, and $11 \%$ by walking people were distracted by these sources.

We found a significant negative relationship between general annoyance caused by noise and overall satisfaction with physical conditions of the workplace. This was because the satisfaction level increased upon a decrease in the noise annoyance level $\left(C_{c}=-0.43, P<0.001\right)$. In addition, the control/privacy dimension had a significant relationship with the overall noise annoyance level $\left(C_{c}=-0.38, \mathrm{P}<0.001\right)$; however, this relationship was less significant than the relationship between the comfort/functionality dimension and the overall noise annoyance level $\left(C_{c}=-0.41, \mathrm{P}<0.001\right)$; however, both dimensions had a significant correlation with the overall noise annoyance level. In this study, we found a significant correlation between the overall noise level annoyance with work experience, age, and perceived mental health, but there was no correlation between perceived physical health and noise level annoyance. Besides, we used the Mann-Whitney test to find the correlation between gender and the overall noise level annoyance. The results showed that there was no significant correlation between these two factors.

\section{Discussion}

The agreement and correlation between the answers ranged from 0.603 to 1 as well 0.714 to 1 , respectively. Besides, the agreement and correlation results showed that there was a good agreement and a high correlation between the answers [33]. The reliability values of the questionnaire using the ICC and the alpha coefficient were 0.876 and 0.930 , respectively. The closer the ICC got to 1, the greater the reliability of the questionnaire became. Regarding the employees' overall sensitivity to noise, we found that they were sensitive to noise. Besides, the reliability values of this part of the questionnaire using the ICC and the alpha coefficient were 0.87 and 0.93 , respectively. In the study of Pierrette, the overall noise sensitivity of individuals was high and sometimes very high. In addition, the reliability of this part of the questionnaire using the alpha coefficient was 0.84 [17]. In the study of Griefahn and Braat-Eggen, the reliability values were 0.87 and 0.81 , respectively $[17,29,34]$. Besides, in the study of Braat-Eggen, the sensitivity of people to noise was moderate [29]. In the study of N. Perrin Jegen, $82 \%$ of the people were generally sensitive to noise [30]. In the study of Braat-Eggen and P. E., people were highly sensitive to noise [35]. According to the results of the present study, $47 \%$ of the employees considered the workplace noise level high (27\%) and very high (20\%), and 35\% considered it annoying (23\%) and very annoying $(12 \%)$. In the study of Pierrette, $56 \%$ of people considered the workplace noise high and very high, and 58\% considered it annoying and very annoying [17]. Similarly, in the study of N. Perrin Jegen, $59 \%$ of people considered the work environment noise high and very high, and 53\% considered it annoying and very annoying [30]. The scores obtained from the overall perceived health assessment showed that the overall perceived health of the employees was very good. The reliability values of this part of the 
questionnaire using the ICC and the alpha coefficient were 0.89 and 0.94 , respectively. Pierrette concluded that the overall perceived health of individuals was very good, and the reliability of this section was 0.89 . Grosjean et al mentioned similar results [17]. N. Perrin evaluated the overall perceived health of individuals as very good [30]. The results of satisfaction with the workplace indicated that the employees generally considered their physical working environment moderately satisfactory. However, if the results of this section was studied according to the two dimensions of control/privacy and comfort/functionality, it would turn out that the employees were less satisfied with the control and private aspects of their physical working environment. The reliability values using the ICC and the alpha coefficient were 0.87 and 0.93 , respectively, for the overall scale, 0.84 and 0.91 for the control/privacy dimension, and 0.90 and 0.95 for the comfort/functionality dimension. In the study by Pierrette et al, satisfaction with the work environment was relatively high, and satisfaction with the control dimension was less than that of the comfort dimension. In addition, the reliability of this part of the questionnaire using the alpha coefficient was 0.88 [17]. In the study by N. Perrin Jegen et al, individuals were relatively satisfied with their work environment, with Braat-Eggen having reported similar results [30]. In the study by Eggen, people were relatively satisfied with their work environment, with their satisfaction in terms of the control dimension having been less than that in terms of the comfort dimension. Besides, the reliability of this part of the questionnaire was 0.79 in that study [29]. The results of the four aforementioned studies were consistent with those of the present study. Based on the findings, there was a significant correlation between the overall noise annoyance and the overall noise level perception in the workplace, with several studies having been consistent with this finding [17, 30]. In this study, the noise sources heard most frequently were the telephones ringing (32\%) and intelligible conversations (24\%), which were "constantly" heard by the employees. The most annoying noise sources were intelligible conversations and telephones ringing, which "totally" annoyed the employees. Although the intelligible conversation ranked second in terms of the most frequently heard noise, it ranked first in terms of annoyance. Inconsistent with the results of the present study, in the studies by N. Perrin Jegen, Pierrette, and Ella Braat-Eggen, intelligible conversations were the most frequently heard and the most annoying noise source $[17,30]$. In this study, we found that $32 \%$ of the employees became distracted while performing specific tasks by operating machines, $34 \%$ by telephones ringing, $26 \%$ by intelligible conversations, $25 \%$ by unintelligible conversations, and $11 \%$ by walking people. In the study by Pierrette et al, the noise of operating machines (58\%), intelligible conversations (67\%), and unintelligible conversations (52\%) distracted employees while performing specific tasks [17]. In the present study, there was a significant negative correlation between the overall annoyance noise level and overall satisfaction with physical conditions of the workplace. Besides, the control/privacy dimension had a significant correlation with the overall annoyance noise level, yet this correlation was less than that between the comfort/functionality dimension and the overall noise annoyance level. There was high consistency with the present study results in several other studies $[17,29,30]$. Based on the findings, there was a correlation between the overall annoyance noise level with work experience, age, and overall perceived mental health. However, there was no correlation between overall perceived physical health and gender with the overall annoyance noise level, with similar results having been reported in Pierrette's study [17]. Besides, the females were more dissatisfied than men with private conversations, annoyance caused by the noise of operating machines, and telephones ringing. In addition, there was a significant correlation between the employees' age and the annoyance caused by the noise of operating machines, which seemed to have been experienced by older employees more than others. In this study, there was a significant correlation between workplace cleanliness and the available equipment. This shows that people satisfied with their workplace cleanliness were satisfied with the available equipment as well. In addition, we found a significant correlation between "controlling the temperature" and "air circulation in the workplace" in the present study. Accordingly, there was a correlation between the factors of "not being seen by others" and "having private conversations", which shows that these two privacy dimension factors were related to each other. In the same vein, N. Perrin Jegen reported findings similar to those in the present study [30].

Among the limitations of the present study, we can refer to the difficulty in accessing individuals, limited numbers of the participants, and limitations due to the COVID-19 pandemic. We suggest the use of this questionnaire and other similar questionnaires in other open-plan offices in future studies. In addition, it is recommended that their results be compared with those of the present 
study to better understand the strengths and weaknesses of this questionnaire.

\section{Conclusion}

This study aimed to assess the effects of noise on the comfort of office employees. Besides, the validity of the questionnaire using the ICC and the alpha coefficient showed to be excellent. In addition, the results showed that the employees of the studied office were sensitive to noise, and their overall satisfaction with the work environment was moderate. Furthermore, 47 and $35 \%$ of the employees considered the workplace noise high and annoying, respectively. We can also conclude that this questionnaire is an efficient and reliable tool for assessing the subjects. Besides, it is a complementary and essential tool for assessing physical conditions when surveying environmental noise in open-plan offices. Additionally, we can use this questionnaire to optimally determine the reforms needed in open offices and to evaluate such reforms.

\section{Acknowledgement}

The authors would like to express their sincere gratitude to all participants of the present study.

Conflict of interest: None declared.

\section{References}

1. Čekan P, Rusko M, ll'ko J, Pietrucha D. Elimination of Excessive Noise at the Open Office Workplace. STU. 2019; 27(44):175-85.

2. Oroke AM, Sarihan E, Ogbuene EB, Ani C. Assessment of Noise Pollution Level in Abakaliki Metropolis, Ebonyi State Nigeria. Theor Empir Res Urban Manag 2020; 15(1):7583.

3. Faroogi ZUR, Sabir M, Latif J, Aslam Z, Ahmad $H R$, Ahmad I, et al. Assessment of noise pollution and its effects on human health in industrial hub of Pakistan. Environ Sci Pollut Res Int 2020; 27(3):2819-28.

4. Münzel T, Sørensen M, Schmidt F, Schmidt E, Steven S, Kröller-Schön $S$, et al. The Adverse Effects of Environmental Noise Exposure on Oxidative Stress and Cardiovascular Risk. Antioxid Redox Signal 2018; 28(9):873-908.

5. Wokekoro E. Public Awareness of the Impacts of Noise Pollution on Human Health. World $\mathrm{J}$ Res Rev 2020; 10(6):27-32.

6. Sheikhmozafari MJ, Alizade PM, Ahmadi O. Validation of the Persian Version of the Workplace Physical-Ergonomic Conditions
Evaluation (PECE) Questionnaire. Int $\mathrm{J}$ Musculoskeletal Pain Prev 2021; 6(3):554-61.

7. Nezami T, Golmohammadi R, Aliabadi $M$, Soltanian A. Investigation acoustic comfort indexes in staff of open plan offices in state banks in Hamadan city. J Occup Hyg Eng 2015; 1(4):60-67.

8. lannace G, Ciaburro G, Trematerra A. Heating, Ventilation, and Air Conditioning (HVAC) Noise Detection in Open-Plan Offices Using Recursive Partitioning. Buildings 2018; 8(12):169.

9. Appel-Meulenbroek R, Steps S, Wenmaekers $\mathrm{R}$, Arentze T. Coping strategies and perceived productivity in open-plan offices with noise problems. J Manag Psychol 2020; 36(4): 40014.

10. Haapakangas A, Hongisto V, Eerola M, Kuusisto T. Distraction distance and perceived disturbance by noise-An analysis of 21 openplan offices. J Acoust Soc Am 2017; 141(1):127.

11. Kang $S$, Ou D, Mak CM. The impact of indoor environmental quality on work productivity in university open-plan research offices. Build Environ 2017; 124:78-89.

12. Haapakangas A, Hongisto V, Varjo J, Lahtinen $M$. Benefits of quiet workspaces in open-plan offices-Evidence from two office relocations. J Environ Psychol 2018; 56:63-75.

13. Seddigh A, Berntson E, Danielson CB, Westerlund $\mathrm{H}$. Concentration requirements modify the effect of office type on indicators of health and performance. $\mathrm{J}$ Environ Psychol 2014; 38:167-74.

14. Oseland N, Hodsman P. A psychoacoustical approach to resolving office noise distraction. J Corp Real Estate 2018;20(4):260-280.

15. Di Blasio S, Shtrepi L, Puglisi GE, Astolfi A. A Cross-Sectional Survey on the Impact of Irrelevant Speech Noise on Annoyance, Mental Health and Well-being, Performance and Occupants' Behavior in Shared and Open-Plan Offices. Int J Environ Res 2019; 16(2):280.

16. Hongisto V, Haapakangas A, Varjo J, Helenius $\mathrm{R}$, Koskela $\mathrm{H}$. Refurbishment of an open-plan office-environmental and job satisfaction. J Environ Psychol 2016; 45:176-91.

17. Pierrette M, Parizet E, Chevret P, Chatillon J. Noise effect on comfort in open-space offices: development of an assessment questionnaire. Ergonomics 2015; 58(1):96-106.

18. Lee PJ, Lee BK, Jeon JY, Zhang M, Kang J. Impact of noise on self-rated job satisfaction and health in open-plan offices: a structural equation modelling approach. Ergonomics 2016; 59(2):222-34.

19. Lee Y, Aletta F. Acoustical planning for workplace health and well-being: a case study in four open-plan offices. Build Acoust 2019; 26(3):207-20.

20. Chandwani A, Chauhan MK, Bhatnagar A. Ergonomics Assessment of Office Desk 
Workers Working in Corporate Offices. Int $\mathrm{J}$ Health Sci Res 2019; 9(8):367-75.

21. Krasnov A, Green ER, Engels B, Corden B. Enhanced speech privacy in office spaces. Build Acoust 2019; 26(1):57-66.

22. Sander ELJ, Marques C, Birt J, Stead M, Baumann O. Open-plan office noise is stressful: multimodal stress detection in a simulated work environment. J Manag Organ 2021:1-17. doi:10.1017/jmo.2021.17.

23. International Organization for Standardization. ISO 3382-3: Acoustics - Measurement of Room Acoustic Parameters - Part 3: Open-Plan Spaces. International Organization for Standardization. Geneva, Switzerland: International Organization for Standardization; 2012. p.15.

24. Sakellaris IA, Saraga DE, Mandin C, Roda C, Fossati S, De Kluizenaar Y, et al. Perceived Indoor Environment and Occupants' Comfort in European "Modern" Office Buildings: The OFFICAIR Study. Int J Environ Res Public Health 2016; 13(5):444.

25. Brocolini L, Parizet E, Chevret P. Effect of masking noise on cognitive performance and annoyance in open plan offices. Appl Acoust 2016; 114:44-55.

26. Seddigh A, Berntson E, Jönsson F, Danielson $\mathrm{CB}$, Westerlund $\mathrm{H}$. The effect of noise absorption variation in open-plan offices: A field study with a cross-over design. J Environ Psychol 2015; 44:34-44.

27. Acun V, Yilmazer S. A grounded theory approach to investigate the perceived soundscape of open-plan offices. Appl Acoust 2018; 131:28-37.
28. Haapakangas A, Hongisto V, Liebl A. The relation between the intelligibility of irrelevant speech and cognitive performance - A revised model based on laboratory studies. Indoor Air 2020; 30(6):1130-46.

29. Braat-Eggen PE, van Heijst $A$, Hornikx $M$, Kohlrausch $A$. Noise disturbance in open-plan study environments: A field study on noise sources, student tasks and room acoustic parameters. Ergonomics 2017; 60(9):1297-314.

30. Perrin Jegen N, Chevret P. Effect of noise on comfort in open-plan offices: application of an assessment questionnaire. Ergonomics 2017; 60(1):6-17.

31. Lee WL, Chinna K, Lim Abdullah K, Zainal Abidin I. The forward-backward and dual-panel translation methods are comparable in producing semantic equivalent versions of a heart quality of life questionnaire. Int $\mathrm{J}$ Nurs Pract 2019; 25(1):e12715.

32. Sundstrom E, Town JP, Rice RW, Osborn DP, Brill M. Office Noise, Satisfaction, and Performance. Environ Behav 1994; 26(2):195222.

33. Mohajan HK. Two Criteria for Good Measurements in Research: Validity and Reliability. Ann Spiru Haret Univ Econ Ser 2017; 17(4):59-82.

34. Griefahn B. Determination of noise sensitivity within an internet survey using a reduced version of the Noise Sensitivity Questionnaire. J Acoust Soc Am 2008; 123(5):3449.

35. Braat-Eggen PE. Auditory distraction in openplan study environments in higher education. [PhD thesis]. Eindhoven, Netherlands: Eindhoven University of Technology; 2020. 